\title{
TINGKAT KEBERHASILAN GROUNDSTROKE FOREHAND DAN BACKHAND PEMAIN TIM NASIONAL TENIS LAPANGAN INDONESIA PADA PERTANDINGAN DAVIS CUP ANTARA INDONESIA VS VIETNAM MARET 2016 DI SOLO.
}

\author{
Fahmi Seff \\ Roy Widyonarto Marison dan Yasep Setiakarnawijaya
}

\begin{abstract}
Abstrak. Penelitian ini bertujuan untuk memperoleh informasi tentang Tingkat Keberhasilan Groundstroke Forehand dan Backhand Pemain Tim Nasional Tenis Lapangan Indonesia pada Pertandingan Davis Cup antara Indonesia VS Vietnam Maret 2016 di Solo secara individu dan team. Tempat penelitian di Solo dan tempat pengambilan data di Lapangan tenis GOR Manahan, Jl.Adi Sucipto, Manahan, Banjarsari, Kota Surakarta, Jawa Tengah. Pada tanggal 4 Maret 2016 - 6 Maret 2016.

Penelitian ini menggunakan metode deskriptif dengan tehnik pengambilan data observasi/survey. Subjek penelitian adalah tunggal putra Tim Nasional Indonsia pada pertandingan Davis Cup antara Indonesia VS Vietnam Maret 2016 di Solo sebanyak 4 partai pertandingan. Berdasarkan pengambilan data dan olah data pertandingan Davis Cup antara Indonesia VS Vietnam adalah Total jumlah keseluruhan pukulan groundstroke forehand dan backhand pemain Indonesia adalah 1228 dengan total slice 278, topsin 904, dan flat 46 dengan prosentase slice $23 \%$, topspin $73 \%$ dan flat $4 \%$. Total keberhasilan pukulan groundstroke forehand dan backhand pemain Indonesia adalah 1000 pukulan dengan rally sebanyak 786 kali, point sebanyak 214 kali. Adapun kegagalan pukulan sebanyak 228 pukulan.

Maka dapat disimpulkan bahwa forehand topspin memiliki tingkat keberhasilan pukulan paling banyak dengan prosentase $83 \%$ dalam perolehan point pemain Tim Nasional tenis lapangan pada pertandingan Davis Cup antara Indonesia VS Vietnam Maret 2016 di Solo. Dengan prosentase keberhasilan tidak point (rally) 57\%, dengan keberhasilan point $26 \%$, dan kegagalan $17 \%$.
\end{abstract}

Kata Kunci : Tenis Lapangan, Groundstroke, Forehand, Backhand,

\section{PENDAHULUAN}

Tenis lapangan adalah olahraga yang dapat di mainkan antara 2 pemain (single) dan 2 pasangan (double). Setiap pemain menggunakan raket untuk memukul bola, tujuan dari permainan ini adalah mencari point dengan memukul bola ke segala arah yang sudah di tentukan dalam peraturannya, sehingga lawan tidak mampu menjakau bola dan terjadi point

Olahraga tenis lapangan berkembangan cukup pesat di Indonesia, hal ini di buktikan dengan suksesnya pertandingan yang di selenggarakan PB PELTI maupun ITF pada saat ini. Kemajuan ini di ikuti dengan prestasiprestasi yang di toreh para pemain tenis Indonesia khusus nya Tim Nasional, seperti

- Gondowidjojo (lahir di Magelang, 21 Januari 1946; umur 70 tahun) adalah pemain tenis kelahiran Indonesia yang menempati ranking teratas sejak tahun 1969. Pria kelahiran Magelang ini memulai kariernya menjadi seorang pemain tenis pada tahun 1958. Pada tahun 1968, Gondowidjojo untuk pertamakalinya menjadi juara nasional tenis. Semenjak saat itu, ia tidak pernah absen dari berbagai pertandingan tenis baik tingkat nasional maupun internasional. Sebagai pemain nasional, ia sering terpilih dalam Tim Nasional untuk mewakili Indonesia pada bertandingan Asian Games, juga piala dunia Davis Cup pada tahun 1972. Gondowidjojo juga berhasil menjadi juara Asia antara lain tahun 1975 dan menjadi juara PON tiga kali secara beruntun tahun 1969, 1973, dan 1977. Dalam SEA Games 1977 di Kuala Lumpur, ia memenangkan dua medali 
emas untuk ganda putra bersama Atet Wijono dan ganda campuran bersama Lita Soegiarto Soetardjo.

- Tintus Arianto Wibowo (lahir di Surabaya, 19 Agustus 1960; umur 55 tahun) merupakan seorang pemain tenis nasional Indonesia. Prestasinya antara lain ialah Medali Perak SEA Games 1981, Juara Beregu Asian Games 1982 dan Medali Perak Pada Asian Games 1986.

- Suharyadi (lahir 14 Februari 1965; umur 51 tahun) adalah mantan petenis Indonesia. Ia bersama dengan Donald Wailan Walalangi pernah bermain di Olimpiade Seoul pada tahun 1988. Selain itu, ia pernah berpasangan dengan Yayuk Basuki di Asian Games 1990 di Beijing mewakili Indonesia di nomor ganda campuran yang meraih medali emas.

- Sri Rahayu Basuki atau lebih dikenal dengan nama Yayuk Basuki (lahir di Yogyakarta, 30 November 1970; umur 45 tahun) adalah mantan pemain tenis dari Indonesia dan dunia yang terkenal pada era tahun 1990-an. Ia memulai karier profesional pada tahun 1990. Pada tahun berikutnya, ia menjadi petenis Indonesia pertama yang menjuarai turnamen profesional. Sepanjang kariernya, Yayuk berhasil memperoleh enam gelar tunggal

Tour WTA dan sembilan gelar dari ganda. Prestasi terbaiknya dalam turnamen Grand Slam adalah mencapai babak perempat final Wimbledon pada tahun 1997. Dia pensiun sebagai pemain tunggal pada tahun 2000, namun tetap menjadi pemain ganda aktif sampai pensiun pada 2013. Peringkat tertinggi yang pernah dicapainya adalah posisi ke-19 untuk bagian tunggal dan ke-9 untuk bagian ganda.

Prestasi prestasi tersebut juga diikuti oleh para juniornya seperti, Suwandi, Bonit Wiryawan, Sulistio Wibowo, Edi Kusdaryanto, Adrian Raturandang, Prima Simpati Aji, Febi Widianto, Sunu Wahyu Trijati, dan saat ini Christoper Rungkat. pria kelahiran Manado yang mampu membawa nama Indonesia terus berkibar dengan menjuarai double
Wimbledon junior dan beberapa pertandingan lainya seperti Davis Cup dan juga Sea Games dengan meraih 3 medali emas pada beregu putra, tunggal perorangan dan ganda campuran di Palembang 2011

Namun sayang prestasi tenis lapangan Indonesia akhir-akhir ini mengalami penurunan, hal ini terbukti dimana Tim Nasional tenis Indonesia gagal meraih emas pada Sea Games Singapore 2015 kemarin, juga kekalahan tim Davis Cup melawan Kuwait April 2015 kemarin di Jakarta. Penurunan prestasi ini amat sangat disayangkan, dimana tim tenis Indonesia yang dikenal sebagai Negara yang mempunyai sejarah prestasi bagus pada perkembanganya harus kalah dengan Negara pakistan yang sangat jarang menghasilkan pemain pada kejuaraan dunia.

Dalam olahraga tenis banyak faktor yang dapat mempengaruhi hasil sebuah pertandingan, seperti fisik, tehnik, taktik, mental, dan strategi. 5 faktor ini saling terkait dan saling menunjang satu dengan yang lain sebagai contoh seorang atlit sangat membutuhkan mental yang kuat agar dia dapat percaya diri dalam mengeksekusi pukulan, dimana atlit sangat membutuhkan tehnik yang baik agar atlit dapat merasa percaya diri dalam memukul dan faktor faktor lainya. namun pada dasarnya olahraga tenis lapangan adalah olahraga permainan yaitu olahraga yang didalam nya sangat membutuhkan skill dan tehnik.

Ada 5 dasar tehnik memukul pada olahraga tenis lapangan, yaiu :

1. Forehand groundstroke

2. backhand groundstroke

3. volley

4. smash

5. Serve

Forehand groundstroke adalah pukulan pukulan yang dilakukan setelah bola memantul di lapangan dimana bola dipukul dimulai dengan posisi open stand atau close stand, dilanjutkan dengan membawa raket kebelakang (backswing) dilanjutkan ayunan raket kedepan dengan contact point terjadi di depan badan diakhiri dengan followthrough yang membawa raket kebelakang kepala (finishing). 
Backhand groundstroke adalah pukulan yang dilakukan setelah bola memantul di lapangan dimana bola dipukul dengan memggunakan punggung tangan dimulai dengan openstand maupun closestand dengan mengayunkan raket dari belakang badan ke depan hingga terjadi follow through dengan contact point di depan badan dan dengan penyelesaian raket di belakang kepala sebelah kanan jika pemain menggunakan tangan kanan, maka punggung tangan kanan yang menggenggam raket akan menghadap ke bola.

Volley adalah pukulan yang dilakukan sebelum bola memantul di lapangan.Smash adalah pukulan yang contact point nya terjadi di atas kepala, yang terjadi ketika lawan melakukan pukulan lob. Serve adalah pukulan untuk memulai sebuah permainan dengan cara bola di lempar keatas kepala dan di lanjutkan dengan pukulan dengan contact point di atas kepala.

Tenis lapangan adalah olahraga yang dapat dimainkan oleh semua kalangan, laki-laki, perempuan dari anak kecil, remaja, dewasa, hingga orang tua namun sangat di anjurkan dari sedini mungkin kita dapat mempelajari tehnik-tehnik dasar pada olahraga ini, sehingga akan terjadi kesempurnaan tehnik pada perkembanganya.

Seperti Roger Federer dari Swiss pemain nomor 1 dunia sejak 2 Februari 2004 -18 Agustus 2008 dan pemegang rekor grand slam sebanyak 16 kali juara. Roger memulai mempelajari olahraga tenis ini pada umur 6th, dan pada umur 14 th ia mulai menjuarai turnamen Swiss open junior, disitulah roger mulai menunjukan bakat dan talentanya, tidak hanya itu pemain kelahiran Binningen, Basel Swiss ini pun semakin tak terhenti, beberapa pemain top pada masa itu pun banyak menjadi korban nya, seperti Pete Sampras, Andre Agasi, Andy Rodick dan lain-lain.

Tidak heran jika hingga umur lebih dari 30 tahun Roger masih bisa bersaing di pertandingan grandslam. kesempurnaan tehnik pukulanya sangat menginspirasi banyak penikmat olahraga ini. Adapun juga pemain Indonesia yang menurut saya mempunyai kesempurnaan tehnik seperti Christoper Rungkat peringkat 1 nasional, Sunu Wahyu Trijati peringkat 2 nasional dan lain-lain.

Kesempurnaan tehnik sangat dibutuhkan dalam olahraga tenis lapangan hal ini disebabkan karena setiap pertandingan yang sedikitnya menghabiskan 2 set dalam 1 pertandingan dan akan menjadikan pemain lebih relax dan tidak mudah cidera.

Tidak hanya itu kesempurnan tehnik juga akan mempermudah pemain dalam menguasai beberapa situasi-situasi dalam permainan tenis. Ada beberapa situasi pada permainan tenis lapangan atau dengan istilah yang sering kita dengar 5 game situation, penjabaranya adalah :

1. Situasi dimana 1 orang (A) serve dan 1 orang lainya (B) return

2. Situasi dimana 1 orang (A) return dan 1 orang lainya (B) serve

3. Situasi dimana A dan B melakukan rally groundstroke (rally)

4. Situasi dimana A melakukan serangan dengan maju kedepan net (Aproachshot)

5. situasi dimana B melakukan aproachshot dan A melakukan passing shot/counter attack dengan mengarahkan bola ke sudut sudut yang sulit di jangkau,

Lima game situation adalah situasi yang pasti terjadi dalam setiap pertandingan, dimana dengan memainkan 5 game situation ini pemain lebih susah di tebak dan cenderung lebih variatif dan tidak monoton dalam permainanya.

Rally groundstroke adalah situasi dimana kedua pemain berada pada baseline untuk membangun serangan dengan memukul bola ketempat yang sulit dijangkau oleh lawan. rally groundstroke dapat dilakukan dengan pukulan forehand maupun backhand dan dengan jenis pukulan yang berbeda-beda seperti topspin, flat, dan slice.

Namun pukulan Topspin yang akan lebih sering digunakan oleh pemain mengingat efek pukulanya yang cenderung berputar saat memantul, dan tinggi dari 
net, sehingga sangat sedikit kemungkinan pemain untuk melakukan unforce error.

Pemain tim Nasional Indonesia adalah pemain yang mampu bersaing dalam pertandingan Internasional meskipun pertandingan Internasional yang di ikuti berada di Asia, seperti pertandingan Men's future dimana pemain Indonesia seperti Christoper Rungkat, Sunu Wahyu Trijati, Adhytia Harisasongko dan juga David Agung Susanto harus mengikuti dan mendapatkan hasil maksimal agar dapat meningkatkan peringkat.

Target prestasi Tim Tenis Nasional Indonesia adalah meraih medali pada pertandingan Asian Games 2018 yang akan di adakan di Indonesia juga pertandingan Davis Cup. Indonesia berada pada zona group II Asia Ocean yang bergabung dengan, Chinese Taipei, Philipines, Sri Langka, Kuwait, Thailand, Malaysia, Vietnam.

\section{KERANGKA TEORI TENIS LAPANGAN}

Permainan tenis adalah suatu aktivitas yang di dalamnya terdapat 2 orang untuk single dan 4 orang untuk double atau mix. Perkembangan olahraga tenis di Indonesia sangat pesat banyak sekolahsekolah tenis, club-club tenis, juga tenis akademi yang didirikan untuk menciptakan atlit berprestasi Tapi disamping itu masih ada bermacam- macam tujuan lain.

Ada orang yang bermain tenis hanya untuk mengisi waktu luang, ada yang bermain tenis untuk bergaul dengan orang lain. Dalam kehidupan modern ini, manusia tidak dapat dipisahkan dari kegiatan olahraga. Baik secara kebutuhan hidup ataupun sebagai gaya hidup guna menjaga tubuh agar tetap bugar dan sehat maupun sebagai arena adu prestasi. Begitu halnya dengan tenis, olahraga ini belakangan menjadi salah satu olahraga yang popular dan cenderung banyak digemari oleh hampir semua lapisan masyarakat dunia, khususnya di Indonesia.

Perkembangan ini disebabkan karena tenis merupakan salah satu cabang olahraga yang dapat dimainkan oleh semua orang mulai dari anak- anak hingga orang dewasa. Tenis lapangan telah mencapai tahap perkembangan sangat pesat dan menarik perhatian sebagian banyak orang, Sejak terbukanya acara-acara pertandingan tingkat dunia dan orang- orang yang ikut serta didalamnya telah mendorong meluasnya olahraga ini ke seluruh dunia, sehingga banyak orang mulai belajar tenis dengan serius tanpa memperdulikan usia maupun jenis kelamin.

Sasaran akhir dalam olahraga prestasi adalah pencapaian prestasi semaksimal mungkin melalui perolehan kemenangan dan pencapaian rekor.

Latihan fisik merupakan salah satu latian untuk semua cabang olahraga terutama cabang olahraga tenis Tujuannya untuk membentuk kondisi tubuh sebagai dasar untuk meningkatkan ketahanan, kelincahan, kecepatan, kekuatan dan kebugaran dalam pencapaian suatu prestasi.

Latihan fisik merupakan salah satu latian untuk semua cabang olahraga terutama cabang olahraga tenis Tujuannya untuk membentuk kondisi tubuh sebagai dasar untuk meningkatkan ketahanan, kelincahan, kecepatan, kekuatan dan kebugaran dalam pencapaian suatu prestasi Mengenai pentingnya aspek latihan fisik diterangkan oleh beberapa ahli mengatakan bahwa: "Sukses dalam olahraga sering menuntut keterampilan yang sempurna dalam situasi stress fisik yang tinggi maka semakin jelas bahwa kondisi fisik memegang peranan yang sangat penting dalam peningkatan prestasi atlet.

Nuriman menjelaskan, "Tenis merupakan olahraga permainan, karena memiliki ciri-ciri yaitu adanya alat yang digunakan dan benda yang dimainkan. Dengan kata lain adanya media yang digunakan berupa raket dan bola”. Tujuan dari permainan tenis adalah memenangkan permainan melalui game dengan cara memukul bola ke arah lapangan lawan melewati net sehingga bola tidak dapat dijangkau oleh lawan dan menghasilkan angka

Setelah kita mengetahui secara umum, maka untuk memulai latihan tenis yang pertama kita harus tahu dan kita kuasai adalah tehnik dasar permainan tenis 
itu, yang terdiri berdasarkan cara memukul yaitu : groundstroke, volley, dan overhead.

Groundstroke merupakan semua pukulan tenis yang kita pukul setelah bolanya menyentuh tanah terlebih dahulu, pukulan groundstroke terbagi lagi menjadi beberapa pukulan, salah satunya yaitu : pukulan drive. Pukulan drive ini diantara nya adalah forehand dan backhand. Kedua pukulan ini menjadi unsur penting dalam permainan tenis dan memukul boladengan cepat, keras, masuk, dan akurat merupakan salah-satu senjata utama dalam bermain tenis. Dan pukulan backhand bisa menjadi senjata utama maupun kelemahan pada setiap pemain

\section{FOREHAND}

Forehand adalah pukulan yang sangat penting dalam permainan tenis lapangan seperti yang dikatakan Elliot et al di buku coaches manual bahwa Pukulan forehand merupakan pukulan atau stroke yang paling penting di tennis Di permainan tennis modern saat ini selama pemain melakukan rally pada baseline, forehand akan menjadi pukulan yang paling sering di gunakan untuk membunuh lawan

Tehnik dasar groundstroke forehand adalah pondasi yang harus dipelajari oleh semua pemain tenis, tehnik gerakan harus sederhana dan mudah. Penguasaan teknik tingkat awal yang terdiri dari gerakan dasar dari proses gerak, bersifat sederhana dan mudah dilakukan

Teknik groundstroke forehand secara keseluruhan dapat diuraikan sebagai berkut :

a. Tahap persiapan.

Pemain berdiri dengan kaki sejajar dan dibuka selebar bahu, lutut agak ditekuk menghadap ke jaring atau net. Tangan kanan memegang pada grip raket bagian bawah dan tangan kiri memegang pada leher raket. Fokuskan padangan pada datangnya bola b. Tahap pelaksanaan

Setelah lawan memukul bola dan bola datang ke sebelah forehand, lakukan backswing dan body turn. Tinggi Backswing tegantung dari tingginya bola yang datang. Hal ini dilakukan dengan memutar pinggul secara vertical. berat badan bertumpu pada kaki kanan. Pukulan dapat dilakukan dengan posisi closestand atau openstand yang disesuaikan dengan arah bola yang akan dipukul

c. Perkenaan raket

Bersamaan dengan perpindahan berat badan dari kaki kanan ke kaki kiri atau dari kaki belakang ke kaki depan, ayunkan raket ke depan, yaitu dari bawah ke atas disertai dengan putaran pinggul, lutut ditekuk dan genggaman diperkuat. Gunakan tangan kiri untuk menjaga keseimbangan. Usahakan perkenaan bola dengan raket di depan pinggul agak ke samping dengan jarak yang paling sesuai. Pada umumnya bola harus dipukul antara lutut dan bahu

d. Gerak lanjut

Ayunkan raket dilanjutkan sampai kedepan ke arah net dan Tangkap raket tersebut dengan tangan kiri dilanjutkan sampai ke telinga dengan siku menekuk
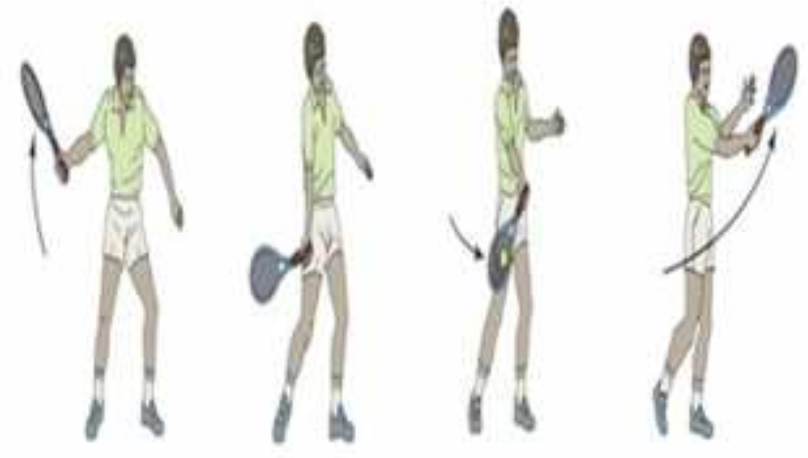

Gambar 1: groundsroke forehand Sumber :

forehanddropshot.files.wordpress.com

\section{The Flat Forehand}

Persiapan sebelum memukul : sebelum bola datang memantul raket harus sudah di ayunkan kebelakang dengan posisi badan menghadap ke lawan dengan posisi tangan kanan menarik raket ke belakang dan tangan kiri di depan badan atau menunjuk ke bola. 
Hitting the ball

Saat melakukan pukulan lengan dan raket melakukan gerakan loop dan mendekati bola dan usahakan memukul bola dengan keadaan bola sedang melakukan gaya ke atas dan kepala raket berada sejajar dengan bola. pada saat yang bersamaan berat badan bergeser, dari tumpuan kaki kanan ke kaki kiri

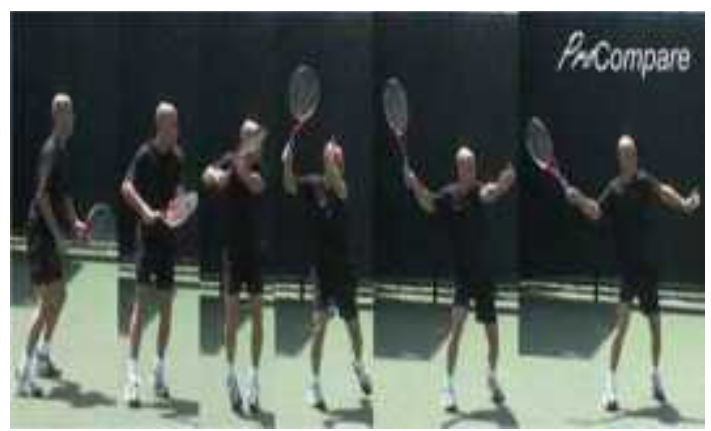

Gambar 2 : forehand flat

Sumber

http://www.procomparetennis.net/media.jpg

\section{Follow through}

Gerak Lanjut raket ke arah target seakan mengikuti bola, dan pergerakan raket itu hampir sepenuhnya menghadap ke permukaan net, pergerakan raket kedepan dan sedikit ke atas hingga pergelangan tangan kanan mendekati bahu kiri dan sisi yang kena bola menghadap ke luar

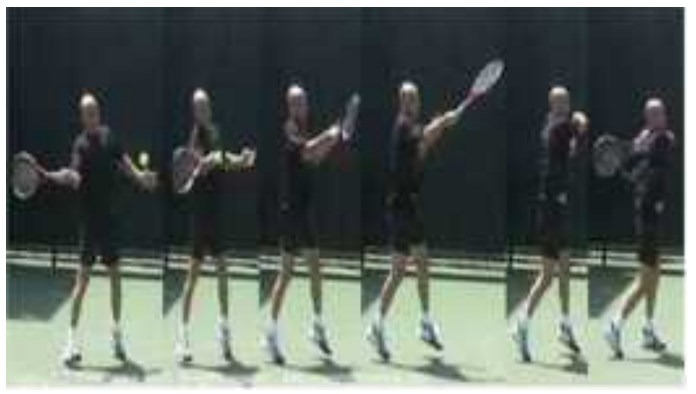

Gambar 3. Follow through

Sumber :

http://www.procomparetennis.net/media.jpg

\section{b. The Top Spin Forehand}

Top spin shot adalah pukulan yang sangat berguna dan banyak di gunakan pemain tenis modern sekarang ini hampir semua pemain dari intermediate, advance maupun pro player menggunakan pukulan ini dalam tehnik pukulanya. pukulan top spin dapat di gunakan untuk menyerang maupun bertahan Kecepatan putaran bola dapat mempengaruhi pantulan bola saat menyentuh permukaan lapangan.pantulan bola menjadi tinggi dan panjang putaran bola tersebut terjadi akibat gesekan bola dengan senar raket yang sangat cepat $\mathrm{Hal}$ ini dijelaskan oleh Bambang Krisdasuwarso bahwa mengatakan "semua tidak akan dapat beregerak jika tidak terjadi gesekan diantara kedua benda yang bersentuhan, hal inilah yang disebut dengan gaya (friction force)

Besarnya gaya ini tergantung dari materi atau bahan benda yang digunakan.masingmasing memiliki tingkat koefisiensi gesek yang berbeda". Pukulan ini dapat merobek sisi bidang kecil dari lapangan lawan, maka dari itu tembakan dapat ditempatkan dengan akurasi

\section{Hitting the ball}

Saat melakukan pukulan, lengan dan raket melakukan gerakan loop dan badan mendekati bola. Usahakan memukul saat bola telah kehilangan gaya ke atas (sedikit menurun) dan eksekusi terakhir, pukul dengan kepala raket datang dari bawah bola menuju

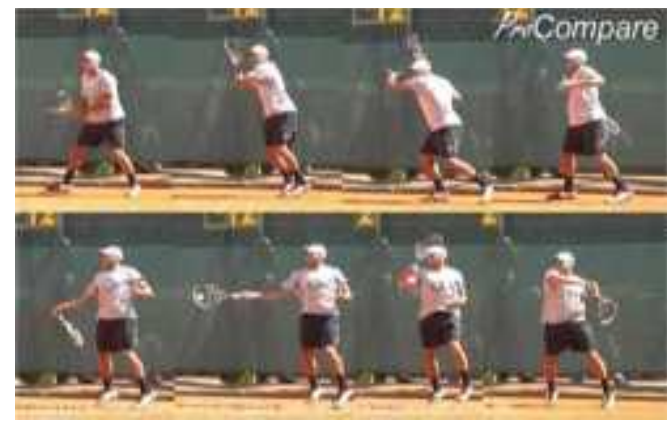

Gambar 4 : Forehand Spin

Sumber :

http://www.procomparetennis.net/media.jpg Ada 3 perbedaan dalam mekakukan pukulan spin with forward rotation

a. The drive (tembakan dengan little forward rotation)

b. The lift (dengan banyak forward rotation )

c. The heavy top spin (spesial shot dengan melakukan maximum forward rotation)

- Underspin/Slice Forehand yaitu Pukulan bertahan 


\section{The Drive}

Jenis pukulan drive menyebabkan bola lebih tajam dan datar namun pukulan ini hanya sebagai pukulan yang dilakukan saat keaadan tertentu saja seperti blocking atau mengembalikan pukulan yang datangnya sangat keras dan cepat, juga pukulan passing shot yang dibutuhkan kecepatan pengambilan keputusan saat memukulnya. Biasanya pukulan drive ini digunakan untuk counter attack terhadap serangan dari lawan.

\section{The lift}

Lift stroke adalah pukulan yang dilakukan dengan menggunakan kecepatan raket yang di bantu dengan gerakan pergelangan yang sangat cepat dan kuat sehingga bola yang dihasilkan sangat pendek dan tajam, lift stroke ini di kategorikan sebagai pukulan menyerang karena sifatnya yang meyulitkan lawan, pukulan ini sangat sering di gunakan ketika lawan melakukan aproachshot yaitu gerakan maju ke net, pukulan ini dilakukan dengan posisi raket dibawa bola dan dipukul sedikit dorongan lalu di lanjutkan dengan banyak gesekan dengan rotasi raket menuju ke bahu kiri atau ke atas kepala dan biasanya bola di arahkan menyilang atau cross court (Moderate Spin).

\section{Heavy Top spin}

Pukulan heavy topspin adalah pukulan topspin yang apabila memantul menyebabkan pantulan yang sangat tinggi, itu alasan kenapa heavy topspin sangat special digunakan untuk passing shot terhadap lawan ketika maju ke net, karena heavy topspin sangat sulit untuk di volley. Untuk memukul heavy topspin pergelangan harus lentur dan kuat, karena pukulan jenis ini membutuhkan kecepatan lengan dan kecepatan raket serta kemampuan tehnik yang tinggi juga timing yang akurat:

- posisi raket herus lebih rendah dibawah bola

- kecepatan raket harus sangat tinngi agar bola dapat meluncur ke depan

- pada saat contact point dengan bola pukulan harus lebih cepat
- kepala raket mengenai bagian bawah bola

- lintasan raket bergerak dari bawah menuju bahu kiri atau atas kepala

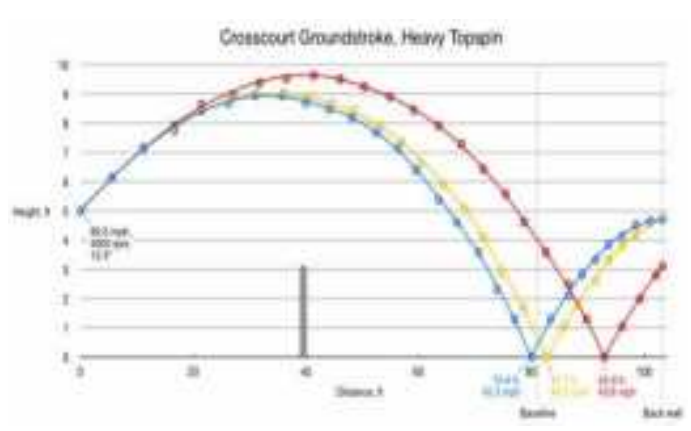

Gambar 5 : Heavy Top Spin Sumber :

www.biomechanicsoftennis.blogspot.com

\section{Underspin/Slice Forehand}

Pukulan underspin atau slice forehand adalah pukulan bertahan. Banyak pemain yang menggunakan pukulan ini dalam keadaan terdesak/bertahan. pukulan slice forehand ini sangat efektif dalam menetralisir serangan. Setiap pemain bagus pasti dapat melakukanya. Tehnik pukulan slice ini dapat digunakan pada situasi return servis, pengambilan bola yang terlampau tinggi atau pada saat melakukan rally pada baseline,biasanya kebanyakan pemain menggunakan pukulan slice ini untuk mermperlambat ritme permainan.

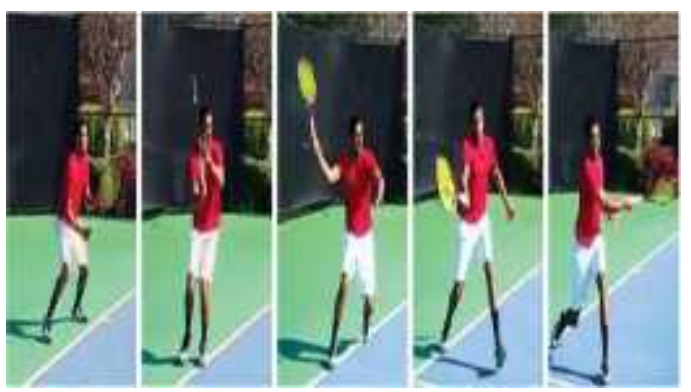

Gambar 6 : Forehand slice

Sumber :

http://www.procomparetennis.net/media.jpg 


\section{BACKHAND}

Backhand adalah pukulan yang dilakukan dengan menggunakan punggung tangan yang memukulnya dengan cara mengayunkan raket dari belakang ke depan hinnga terjadi contact point serta followthrought. Jenis-jenis backhand:

a. Backhand satu tangan

Terdapat beberapa kelebihan dalam menggunakan backhand satu tangan, pertama jangkauannya yang panjang sehingga bola-bola dapat ditangani lebih mudah. Terdapat dua jenis grip yang biasa digunakan dalam melakukan backhand satu tangan, yaitu eastern Backhand dan western backhand grip.

Tahap-tahap melakukan backhand drive pada permainan tenis

\section{Backhand 1 tangan}

- Telapak tangan dan bukujari dari tangan pertama pada ujung gagang di putar $1 / 4$ putaran kedalam dari pegangan eastern backhand grip.

- Kekuatan bertumpu pada belakang gagang, dengan tingkat kelenturan tertentu.

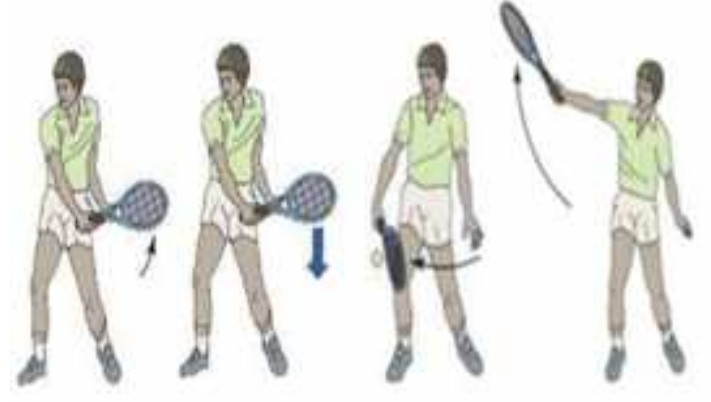

Gambar 7 : Backhand drive 1 tangan

Sumber :

http://www.procomparetennis.net/media.jpg

b. Backhand dua tangan

Backhand dua tangan merupakan pukulan yang banyak digunakan dibandingkan dengan backhand satu tangan. Keuntungan dari backhand dua tangan adalah pukulan yang dihasilkan lebih konsisten dan keras hal ini di sebabkan karena raket yang lebih stabil pada saat contact point. Kekurangan dari backhand dua tangan adalah jangkauan dimana rotasi tangan yang terbatas saat contact point.
Grip yang di pakai dalam melakukan pukulan backhand dua tangan adalah grip continental untuk tangan kanan dengan pegangan berada di dasar grip dan tangan kiri berada di atasnya dengan grip semi western. Untuk selengkapnya tahapan melakukan backhand dua tangan adalah sebagai berikut:

Grip

- Tangan kanan menggunakan grip continental, kemudian tangan kiri menggunakan grip Forehand Eastern / semi western

- Pemain pemula biasa menggunakan genggaman forehand eastern (kanan \& kiri) dan kemudian jika mereka menjadi lebih berpengalaman, maka mereka disarankan mengubah grip tersebut.

Posisi Siap

- Sama seperti besiap ketika ingin memukul pukulan forehand, dengan posisi kuda-kuda, dengan lutut di tekuk dan relax

- Saat Persiapan

- Putaran bahu dan ayunan kebelakang

- Saat terjadi putaran bahu dan pinggul, grip berubah selama bahu berputar.

- Berat badan bertumpu pada kaki kiri.

- Tangan kanan dan kiri bergerak bersamaan.

- Raket kebelakang dan turun, di bawah ketinggian bola yang datang.

- Racket face menyentuh bola yang datang.

- Lutut ditekuk untuk menambah kekuatan pukulan.

Saat Memukul

- Ayunan kedepan dan tepatkan bola pada raket.

- Langkah pemain mengarah ke bola yang datang sebelum memulai ayunan kedepan.

- Titik impact lebih di depan sebelah luar badan kita.

- Tangan kanan lurus saat terjadi impact.

- Titik impact berada didepan panggul sebelah kanan.

- Lintasan ayunan dari bawah ke atas untuk mencapai sasaran. 
Gerak Lanjutan

Raket terus mengikuti bola dalam satu gerakan yang berkelanjutan.

Kedua tangan berakhir setinggi bahu.

Tapak kaki sebelah kiri menghadap ke belakang sehingga tumit kiri terangkat.

Tangan berakhir lurus di depan tubuh dan siku dapat ditekuk, tangan melilit bahu

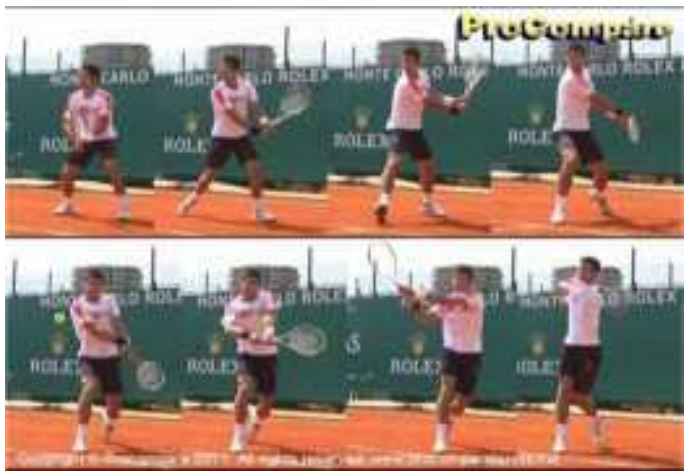

Gambar 8 : Backhand drive

Sumber :

http://www.procomparetennis.net/media.jpg

Tahap-Tahap Melakukan Pukulan Backhand Dan Jenis Pukulanya

\section{b. The Flat Backhand}

Backhand flat adalah pukulan yang dimana raket dan bola bertemu dalam keadaan sejajar, pada tenis jaman dulu sangat jarang digunakan, karena jenis permainan dan grip yang sangat susah untuk melakukan pukulan ini, namun dengan berkembangannya tenis modern pukulan jenis flat ini terus meningkat dalam presentase pukulan, biasanya kebanyakan pemain akan lebih sering melakukan pada return serve atau mengembalikan bola- bola keras karena tehniknya yang simple juga bola yang di hasilkan akan sangat cepat dan tajam.

\section{Hitting the ball}

Persiapan sebelum memukul : dari posisi siap bahu dan lengan serta badan berpindah ke sebelah kiri. Sebelum memukul tarik raket kebelakang dengan posisi kaki kiri dibelakang dan kaki kanan di depan (square) dengan badan menghadap ke samping lapangan dan bahu kanan mengarah ke lawan, ayunkan raket kedepan dengan posisi kedua tangan (two handed) lurus sejajar dengan bahu. Di anjurkan contact point di depan badan dan bola masih dalam keadaan gaya ke atas setelah memantul, agar pukulkan yang di hasilkan dapat datar dan tajam.

\section{Follow through}

Gerak lanjutan raket ke arah target seakan mengikuti bola, dan pergerakan raket itu hampir sepenuhnya menghadap ke permukaan net, pergerakan raket kedepan dan sedikit ke atas.

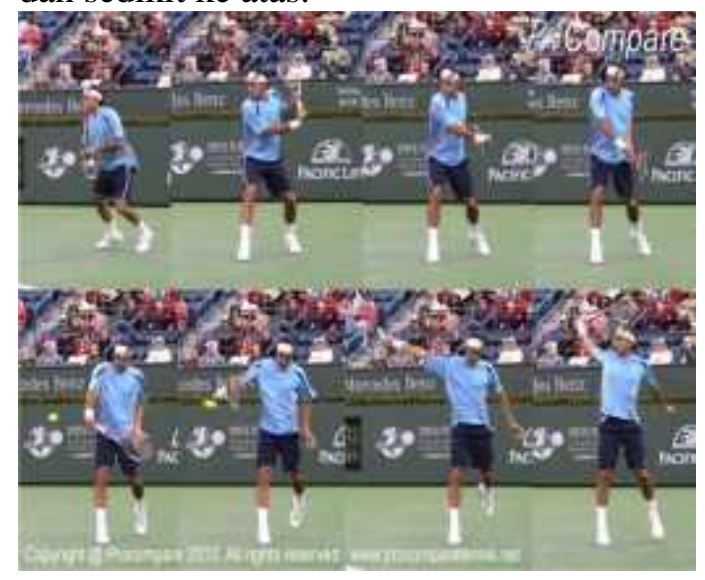

Gambar 9: Backhand drive

Sumber :

http://www.procomparetennis.net/media.jpg

\section{c. The Top Spin Backhand}

Top spin backhand adalah pukulan yang dapat dilakukan dengan 2 tanggan maupun dengan 1 tangan yang cara memukulnya dengan menggesek bola ke atas pada saat contact point sehingga bola yang dihasilkan memantul tinggi setelah mengenai permukaan lapangan.

\section{Hitting the ball}

Selama stroke, lengan dan raket melakukan gerakan loop dan mendekati bola dan usahakan memukul bola dengan keadaan bola sedang melakukan gaya sedikit menurun dan pukul dengan kepala raket dating dari bawah bola agar terjadi putaran yang kuat. Tahap - tahap memukul:

- posisi raket herus lebih rendah dari bola / dibawah bola.

- pada saat contact point dengan bola akselerasi raket harus maksimal. 
- kepala raket menggesek bola dari bawah ke atas.

- raket mengikuti lintasan gerak lanjut menuju bahu kanan atau atas kepala.

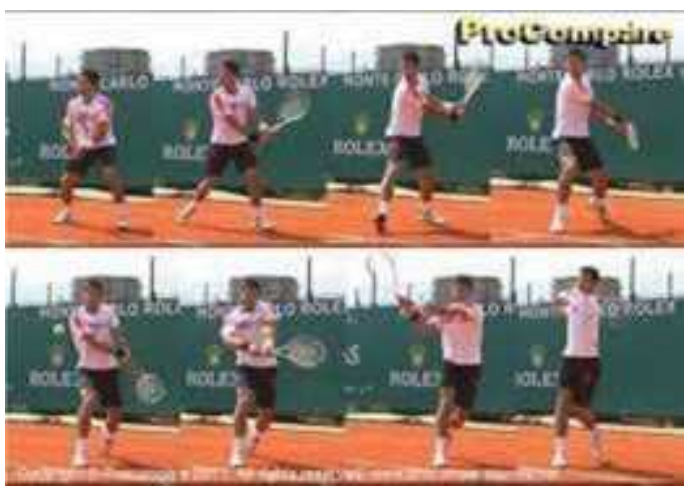

Gambar 10 : Backhand drive

Sumber :

http://www.procomparetennis.net/media.jpg

\section{a. Underspin /Slice Backhand}

Kebanyakan pukulan underspin atau slice backhand adalah pukulan bertahan. Banyak pemain yang menggunakan pukulan ini dalam keadaan terdesak/bertahan. Pukulan slice atau underspin ini sangat efektif dalam keadaan tertentu. Setiap pemain bagus pasti dapat melakukanya.

Pukulan slice ini dapat digunakan pada saat return servis, pada bola yang cukup tinggi atau pada saat melakukan rally pada baseline, biasanya kebanyakan pemain menggunakan pukulan slice ini untuk mermperlambat ritme permainan.I

Sekilas penggunaan pukulan slice ini hampir sama dengan slice forehand, namun slice backhand lebih sering digunakan pemain dalam permainan dibandingkan forehand slice, begitupun kegunaannya jika forehand slice lebih banyak di gunaakan untuk pukulan bertahan saja namun berbeda dengan backhand slice, backhand slice dapat digunakan dalam situasi apapun.

Pukulan ini sangat sering dilakukan untuk approachshot dimana hanya dibutuhkan sedikit dorongan dan penempatan yang bagus akan menghasilakan bola yang akurat, tajam, dan menyusahkan lawan.

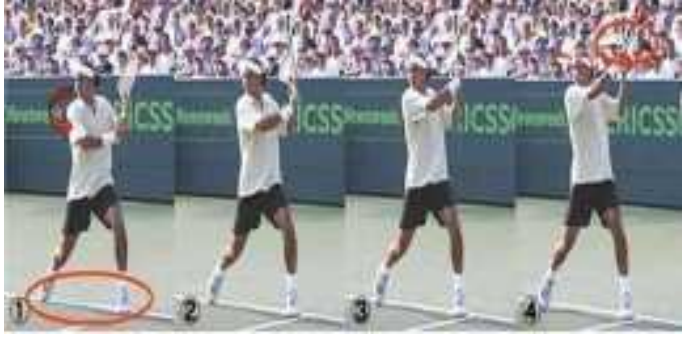

Gambar 11 : Backhand slice

Sumber : http://www.tenniscompanion.jpg

Pukulan underspin akan menghasilkan putaran bola seperti gambar berikut :

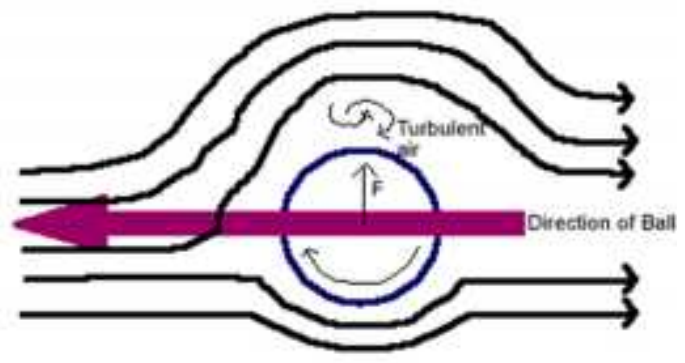

Gambar 12 : Bola Backspin

Sumber :

www.biomechanicsoftennis.blogspot.com

\section{PERTANDINGAN TENIS}

Tenis adalah suatu cabang olaharaga yang memainkan 2 orang (single) dan 4 orang (double)/(mix), yang cara bermainya dengan menggunakan raket, bola tenis dan dengan sarana prasarana lainya. Jenis- jenis pertandingan didalam tenis lapangan ada 2, yaitu Perorarangan dan beregu. Pada perorangan di pertandingkan nomor tunggal, ganda, dan mix. Semua yang di pertandingkan mengikuti kelompok umurnya masingmasing. kategori umur yang di pertandingkan junior ( 10 th $\mathrm{pa} / \mathrm{pi}, 12$ th $\mathrm{pa} / \mathrm{pi}, 14$ th $\mathrm{pa} / \mathrm{pi}, 16$ th $\mathrm{pa} / \mathrm{pi}$ dan 18 th $\mathrm{pa} / \mathrm{pi}$ ), sedangkan untuk kategori senior dipertandingkan kelompok umur 18 th pa/pi ke atas.

Pada setiap pertandigan tenis dimainkan dengan peraturan thebest of three final set yaitu 2 set apabila terjadi satu sama di lanjutlan dengan penentuan set. Masing-masing set terdapat 6 game dan masing-masing game terdapat 3 point seperti (15-0) (30-0) (40-0) dan game, apabila terjadi 40-40 maka terjadi deuce 
dan mencari 2 point untuk mendapatkan game ini.

Pada pertandingan beregu terdapat format pertandingan didalamnya. Seperti, pertandingan Davis Cup yang didalamnya memainkan 2 tunggal yang dilakukan secara silang, dan 1 ganda dan diselenggarakan dalam 3 hari.

\section{KERANGKA BERFIKIR}

Pada dasarnya Indonesia memiliki prestasi cukup baik pada cabang olahraga tenis lapangan, dimana Indonesia meiliki pemain-pemain yang mampu bersaing pada kejuaraan Dunia, Asia, maupun Asean. Namun pada beberapa tahun terakhir prestasi Tenis lapangan Indonesia mengalami kemunduran dimana Indonesia gagal meraih medali Emas pada pertandingan SEA GAMES di Singapore 2015 juga penampilan yang kurang maksimal pada pertandingan Davis Cup 2015 melawan Pakistan hingga akhirnya Indonesia harus kalah dengan score 2-3.

Dari masalah tersebut membuat penulis ingin menganalisis Tingkat Keberhasilan Groundstroke Forehand dan Backhand Pemain Tim Nasional Tenis Lapangan Indonesia pada Pertandingan Davis Cup antara Indonesia VS Vietnam Maret 2016 di Solo sehingga mendapatkan hasil penelitian yang berguna dalam meningkatkan prestasi tenis Indonesia.

Berdasarkan kajian teori yang telah dijelaskan di atas maka disusun kerangka berpikir bahwa peneliti memerlukan data tingkat keberhasilan. Tingkat keberhasilan dapat diperoleh dengan mengetahui jumlah pukulan yang berhasil dan jumlah pukulan yang gagal dengan menggunakan teknik pengumpulan data.

Keberhasilan yang dimaksud adalah kondisi dimana bola hasil pukulan groundstroke masuk ke daerah lawan, baik terjadi rally atau menghasilkan point (winner), maka pukulan dianggap berhasil, Sedangkan, jika bola hasil pukulan groundstroke tidak masuk ke daerah lawan, baik keluar lapangan (out) atau menyakut di net, maka pukulan dianggap gagal.

Untuk lebih jelasnya kerangka berpikir dalam penelitian ini dapat digambarkan dalam skema di bawah ini :

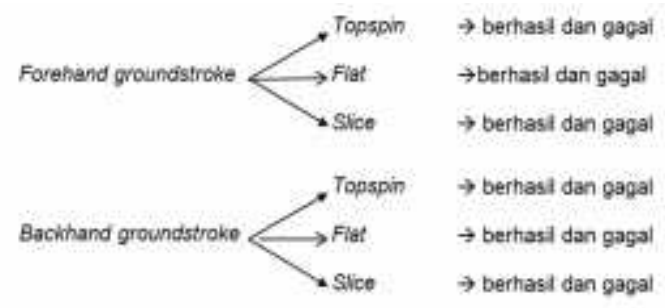

Dari kerangka tersebut penulis akan mencari :

- kontribusi keberhasilan pukulan forehand topspin dalam perolehan point

- kontribusi keberhasilan pukulan forehand flat dalam perolehan point

- kontribusi keberhasilan pukulan forehand slice dalam perolehan point

- kontribusi keberhasilan pukulan backhand topspin dalam perolehan point

- kontribusi keberhailan pukulan backhand flat dalam perolehan point

- kontribusi keberhasilan pukulan backhand slice dalam perolehan point

\section{METODE PENELITIAN}

Metode penelitian adalah karya ilmiah yang digunakan untuk meneliti suatu data pada tujuan tertentu1. Metode penelitian ini termasuk dalam metode deskriptif dengan teknik pengambilan data observasi/survey. Teknik dari penelitian ini adalah survey dalam bentuk metode penilaian diantaranya :

a. Observasi bebas dengan melihat langsung.

b. Observasi tertulis dengan chart penelitian yang berisi kolom-kolom tabel dan baris-baris tabel untuk mencatat data.

c. Observasi dengan tehnik dokumenter

\section{POPULASI DAN TEHNIK PENGAMBILAN SAMPEL}

\section{Populasi}

Populasi adalah wilayah generalisasi tang terdiri atas: obyek/subyek yang mempunyai kualitas dan karateristik tertentu yang ditetapkan oleh peneliti untuk dipelajari dan kemudian ditarik kesimpulannya

\section{Sampel}


Teknik pengambilan sampel menggunakan teknik purposive sampling yaitu, peneliti mempunyai pertimbangan-pertimbangan tertentu di dalam pengambilan sampel,3 Sampel dalam skripsi ini adalah:

- Aktifitas pukulan Groundstroke pemain Tim Nasional Tenislapangan Indonesia pada pertandingan Davis Cup antara Indonesia vs Vietnam Maret 2016 di Solo.

- Pemain Tim Nasional Tenis lapangan Indonesia yang bermain single

pada pertandingan Davis Cup antara Indonesia vs Vietnam Maret 2016 di Solo.

\section{INSTRUMEN PENELITIAN}

Instrumen dalam penelitian ini, menggunakan blanko penelitian yang berisi kolom-kolom tabel dan baris-baris tabel untuk tiap keberhasilan, rally dan kegagalan Pukulan dasar Tenis Seperti Groundstroke forehand dan backhand flat, topspin, atau slice.

Pengumpulan data dilakukan untuk mengetahui keberhasilan dan kegagalan pukulan Groundstroke forehand dan backhand flat, topspin, atau slice selanjutnya akan diperoleh data yang bersifat kuantitatif. Suharsimi dalam bukunya mengatakan: Data kuantitatif tersebut dijumlahkan, dibandingkan dengan jumlah yang diharapkan dan diperoleh persentasi

\section{TEKNIK PENGUMPULAN DATA}

Data dikumpulkan dengan teknik observasi, dengan cara mengisi blangko penelitian yang berisi kolom-kolom tabel dan baris-baris tabel di isi pada saat sebuah tim melakukan keberhasilan dan kegagalan Pukulan. Groundstroke forehand dan backhand flat, topspin, atau slice, Keberhasilan dan kegagalan ditulis dengan garis. Keberhasilan yang dimaksud adalah kondisi dimana bola hasil pukulan groundstroke masuk ke daerah lawan, baik terjadi rally atau menghasilkan point (winner), maka pukulan dianggap berhasil. Sedangkan, jika bola hasil pukulan groundstroke tidak masuk ke daerah lawan, baik keluar lapangan (out) atau menyakut di net, maka pukulan dianggap gagal
Teknik Analisa Data

Penelitian ini bertujuan mencari gambaran kemampuan Pukulan Groundstroke forehand dan backhand flat, topspin, atau slice, sehingga teknik analisis data yang digunakan adalah teknik deskriptif dengan persentase :

1. Menghitung prosentasi atau disebut frekuensi relatif (f rel)

2. Menghitung aktivitas pukulan (N)

3. Menginterprestasikan setiap kriteria kemapuan masing-masing, menghitung keberhasilan dan kegagalan pukulan Groundstroke forehand dan backhand flat, topspin, atau slice dalam permainan tenis lapangan.

Untuk menghitung skor rata-rata digunakan rumus:

$\mathrm{f} \%=\frac{\mathrm{f} 1}{\mathrm{~N}} \times 100 \% 5$

\section{DESKRIPSI DATA}

Setelah dilakukan pengambilan data, kemudian dikumpulkan dan dihitung dengan petunjuk teknik serta pengolahan data, sebagai hasil prosentase rata-rata tingkat keberhasilan groundstroke pemain tenis Tim Nasional Indonesia pada pertandingan Davis Cup Indonesia VS Vietnam pada bulan Maret 2016 di Solo. Perhitungan dan data lengkap terdapat pada

Tabel 1 Tingkat Keberhasilan Pukulan Forehand Groundstroke Timnas Davis Cup Indonesia Vs Vietnam

\begin{tabular}{|c|c|c|c|c|c|c|c|c|c|c|}
\hline \multirow{4}{*}{\multicolumn{2}{|c|}{ PEHGOLAH DATA }} & \multicolumn{9}{|c|}{ Groundstroke of Tennis } \\
\hline & & \multicolumn{9}{|c|}{ Forehand } \\
\hline & & \multicolumn{3}{|c|}{ Top Spin } & \multicolumn{3}{|c|}{ Flat } & \multicolumn{3}{|c|}{ SBice } \\
\hline & & Wh & Raily & Faill & Win & Rally & Faif & Win & Raily & Fall \\
\hline 1 & $\begin{array}{l}\text { Christopet } \\
\text { Rungkat }\end{array}$ & 70 & 117 & 47 & 1 & 9 & 0 & 1 & 4 & 1 \\
\hline 2 & $\begin{array}{c}\text { Adhitya } \\
\text { Haris:asongko }\end{array}$ & 74 & 203 & 49 & 3 & 2 & 3 & 3 & 20 & 10 \\
\hline \multirow{5}{*}{\multicolumn{2}{|c|}{ JUAALAH }} & 144 & 320 & 96 & 4 & 11 & 3 & 4 & 24 & 11 \\
\hline & & \multicolumn{3}{|c|}{560} & \multicolumn{3}{|c|}{18} & \multicolumn{3}{|c|}{39} \\
\hline & & \multicolumn{9}{|c|}{617} \\
\hline & & \multicolumn{9}{|c|}{ Statistik Pukulan Groandstroke } \\
\hline & & \multicolumn{9}{|c|}{ Forehand } \\
\hline \multirow{5}{*}{\multicolumn{2}{|c|}{ PERSENTASE }} & \multicolumn{9}{|c|}{$50 \%$} \\
\hline & & \multicolumn{3}{|c|}{ Top Spin } & \multirow{2}{*}{\multicolumn{3}{|c|}{$\frac{\text { Flat }}{3 \%}$}} & \multicolumn{3}{|c|}{ Slice } \\
\hline & & \multicolumn{3}{|c|}{9176} & & & & \multicolumn{3}{|c|}{$6 \%$} \\
\hline & & \multicolumn{2}{|c|}{ Succes } & Fall & \multicolumn{2}{|c|}{ Succes } & Faif & \multicolumn{2}{|c|}{ Succes } & Fail \\
\hline & & \multicolumn{2}{|c|}{$63 \%$} & 1736 & \multicolumn{2}{|c|}{$83 \%$} & 1796 & \multicolumn{2}{|c|}{$72 \%$} & $28 \%$ \\
\hline
\end{tabular}


Tabel 2 Tingkat Keberhasilan Pukulan Forehand Groundstroke Timnas Davis Cup Indonesia Vs Vietnam

\begin{tabular}{|c|c|c|c|c|c|c|c|c|c|c|}
\hline \multirow{4}{*}{\multicolumn{2}{|c|}{ PEMGOLAH DATA }} & \multicolumn{9}{|c|}{ Groundstroke of Tennis } \\
\hline & & \multicolumn{9}{|c|}{ Backhand } \\
\hline & & \multicolumn{3}{|c|}{ Top Spin } & \multicolumn{3}{|c|}{ Flat } & \multicolumn{3}{|c|}{ Slict } \\
\hline & & Win & Raly & Fall & Win & Rally & Foll & Win & Raily & Fall \\
\hline 1 & $\begin{array}{l}\text { Chinstopes } \\
\text { Rungiat }\end{array}$ & 19 & 51 & 14 & 3 & 7 & 3 & 4 & 20 & 9 \\
\hline 2 & $\begin{array}{l}\text { Achitya } \\
\text { Harisascapo }\end{array}$ & 20 & 178 & 52 & 2 & 13 & 0 & 14 & 152 & 40 \\
\hline \multirow{5}{*}{\multicolumn{2}{|c|}{ JUMLAY }} & 39 & 239 & 68 & 5 & 20 & 3 & 13 & 172 & 49 \\
\hline & & \multicolumn{3}{|c|}{344} & \multicolumn{3}{|c|}{28} & \multicolumn{3}{|c|}{239} \\
\hline & & \multicolumn{9}{|c|}{611} \\
\hline & & \multicolumn{9}{|c|}{ Statisok Pukulan Groundstroke } \\
\hline & & \multicolumn{9}{|c|}{ Backhand } \\
\hline \multirow{5}{*}{\multicolumn{2}{|c|}{ PERSENTASE }} & \multicolumn{9}{|c|}{$50 \%$} \\
\hline & & \multirow{2}{*}{\multicolumn{3}{|c|}{$\frac{\text { Top Spin }}{56 \%}$}} & \multirow{2}{*}{\multicolumn{3}{|c|}{$\frac{\text { Flat }}{5 \%}$}} & \multicolumn{3}{|c|}{ Slice } \\
\hline & & & & & & & & \multicolumn{3}{|c|}{$39 \%$} \\
\hline & & \multicolumn{2}{|c|}{ Succes } & Faid & \multicolumn{2}{|c|}{ Succese } & Fail & & ccos: & Fail \\
\hline & & \multicolumn{2}{|c|}{$8+\%$} & $19 \%$ & \multicolumn{2}{|c|}{894} & 1196 & \multicolumn{2}{|c|}{$79 \%$} & $28 \%$ \\
\hline
\end{tabular}

\section{PEMBAHASAN HASIL PENELITIAN}

Dari banyaknya pukulan yang dihasilkan pada pertandingan teresebut, Indonesia dapat melakukan pukulan groundstroke sebanyak 1228 pukulan. Banyaknya pukulan groundstroke dihasilkan melalui pukulan forehand sebanyak 617 pukulan dan pukulan backhand sebanyak 611. Hasil pukulan groundstroke dari forehand dan backhand cukup berimbang dikarenakan tehnik kemampuan pukulan yang hampir sama juga permainan yang variatif, sehingga serangan dapat dilakukan oleh pukulan groundstroke jenis apapun tergantung dari situasi atau datangnya bola.

Pukulan forehand topspin memiliki tingkat keberhasilan pukulan paling besar pemain Tim Nasional tenis lapangan Indonesia pada pertandingan Davis Cup yaitu $83 \%$ dengan keberhasilan pukulan namun tidak point(rally) $57 \%$ dan keberhasilan point $26 \%$ dan kegagalan $17 \%$. Hal ini disebabkan karena pukulan forehand adalah pukulan yang paling nyaman dilakukan dalam keadaan menyerang maupun bertahan, pukulan forehand juga dapat dilakukan dengan bergerak (running shot) dan tetap menghasilkan bola yang keras juga terarah.

Sedangkan topspin adalah pukulan yang memiliki tingkat kegagalan yang sedikit dikarenakan bola yang dihasilkan melambung cukup tinggi dari net dan juga bola yang yang memutar menyebabkan bola lebih cepat turun sehinnga sangat sedikit kemungkinan untuk terjadi atau unforce error. Namun pukulan jenis topspin juga memiliki kelemahan yaitu pantulan yang tinggi saat memantul sehingga membuat lawan mudah untuk mengambalikan pukulan dari pemain Tim Nasional Tenis lapangan Indonesia.

Banyak nya pukulan topspin yang dilakukan membuat pemain Indonesia sangat banyak melakukan rally dan sedikit perolehan point. Hal ini yang mebuat Tim Nasional tenis lapangan Indonesia harus kalah 2-3 dari Vietnam pada pertandingan Davis Cup antara Indonesia VS Vietnam pada bulan Maret 2016 di Solo.

Banyak tingkat keberhasilan point Pemain Tim Nasional Tenis Lapangan Indonesia dihasilkan dari pukulan forehand topspin sebanyak 144 pukulan. Jika dilihat dari karakteristik pukulan, flat adalah jenis pukulan yang paling tepat untuk menghasilkan point namun pukulan flat harus dilakukan dalam posisi dimana bola jatuh berada di dekat badan agar menhasilakn bola yang maksimal, sedangkan pertandingan Indonesia VS Vietnam sangat sengit dimana pemain Vietnam memukul bola kearah zona tidak nyaman pemain indonesia, hal ini yang memaksa pemain indonesia harus menhasilkan point dari pukulan jenis topspin.

Terlihat dari hasil pengamatan tersebut maka forehand topspin merupakan penyelesaian yang terbaik dari pemain tenis tim nasional Indonesia pada pertandingan Davis Cup antara Indonesia VS Vietnam di Solo. Terbukti dengan banyaknya keberhasillan yang diperoleh dibandingkan dengan banyaknya kegagalan pada aktivitas keseluruhan pukulan groundstroke forehand dan backhand pemain tenis tim nasional Indonesia pada pertndingan Davis Cup antara Indonesia VS Vietnam. Pukulan jenis topspin sangat dimanfaatkan dengan baik oleh pemain tenis tim nasional Indonesia untuk mengasilkan point. 
Hal ini terlihat dari banyaknya keberhasilan pukulan dan keberhasilan point yang banyak di hasilkan oleh pukulan forehand topspin. Forehand topspin merupakan pukulan yang yang memiliki prosentase kegagalan paling sedikit di bandingkan pukulan forehand flat maupun forehand slice, melihat karakteristik pukulan jenis topsin yang penuh dengan putaran sehingga sangat jarang untuk terjadi unforce error. Terlihat pada para pemain yang sangat mampu memaksimalkan pukulan forhand tospin dan memiliki penempatan bola yang baik sehingga sulit dikembalikan oleh lawan.

Buruknya prosentase keberhasilan dari forehand topspin juga disebabkan karena tidak konsistennya pemain tenis tim nasional Indonesia dalam melakukan pukulan, dan terlalu terburu-buru dalam megambil keputusan, karena dalam melakukan pukulan setiap pemain membutuhkan tingkat konsentrasi yang tinggi dan keyakinan yang kuat sehingga dapat menghasilkan pukulan yang maksimal.

\section{KESIMPULAN}

Berdasarkan masalah yang dikemukanakan yang didukung oleh deskripsi teori dan kerangka berfikir serta analisis data, maka hasil penelitian dapat disimpulkan sebagai berikut:

1. Total keseluruhan aktivitas groundstroke memiliki prosentase $81 \%$ keberhasilan dan kegagalannya dengan prosentase $19 \%$

2. 2. Total keseluruhan aktivitas groundstroke forehand memiliki prosentase $82 \%$ keberhasilan dan kegagalannya dengan prosentase $18 \%$

3. 3. Total keseluruhan aktivitas groundstroke backhand memiliki prosentase $81 \%$ keberhasilan dan kegagalannya dengan prosentase $19 \%$

4. 4. Total keseluruhan aktivitas groundstroke forehand topspin memiliki prosentase keberhasilan terbanyak dengan $83.3 \%$ keberhasilan dan kegagalannya dengan prosentase $16.7 \%$
5. 5.Total keseluruhan aktivitas groundstroke backhand topspin memiliki prosentase keberhasilan terbanyak dengan $80 \%$ keberhasilan dan kegagalannya dengan prosentase $20 \%$

\section{SARAN}

1. Kita harus memiliki analisis SWOT dalam pertandingan baik sebelum dan sesudah, karena analisis SWOT merupakan instrumen perencanaan strategis yang klasik, yang mudah dilakukan namun memiliki dampak yang cukup membantu tim nasional tenis lapangan Indonesia.

2. Agar pelatih tim nasional tenis lapangan Indonesia dapat menyeimbangkan komposisi program tehnik-tehnik pukulan agar lebih variatif dan tidak monoton, seperti pukulan flat yang seharusya dimiliki pemain sehingga dapat mengasilkan point lebih banyak.

3. Selalu membuat evaluasi dan analisis pada setiap pertandingan yang telah dilakukan agar pertandingan yang akan dihadapi menjadi lebih baik.

4. Pemain hendaklah selalu belajar dan mengetahui bagaimana cara melakukan tehnik pukulan yang baik dan efisien, baik melalui analisis data pertandingan, kompetisi, dan video recorder.

5. Pemain, pelatih, disarankan untuk mempelajari dan menganalisis permaianan lawan.

6. Dan agar selalu diadakan seleksi rutin sebelum pembentukan tim agar terjadi persaingan yang ketat dan juga menghasilkan pemain- pemain yang berkualitas. 


\section{DAFTAR PUSTAKA}

Arikunto Suharsimi, Manajemen Penelitian, Jakarta : Rineka Cipta, 1990

Crespo,Miguel and Miley Dave, Advance Coaches Manual London, ITF, 1998.

Delavier. Frederic, Strength Training Anatomy, English, 2005

Elliot. Bruce, Machar Reid, Miguel Crespo, ITF Biomechanics London, 2003

Gallwey, W. Timothy, Inner Tennis: Playing the game, USA, Random House, 1976

International Tennis Federation, Rules of Tennis 2013 London:ITF, 2013

ITF Level-1, Coaches Manual, Canada, ITF, 1998

Jim. Brown, Tennis: Steps To Success, USA,Leisure press, 1989.

Katili. A.A., Olahraga Tennis, Jakarta,Yayasan Merpati,1973

Kridasuwarso. Bambang, Biomekanika Olahraga, Jakarta, UNJ, 2013

Marso. Soemarsono, Kursus Instruktur Tenis PELTI, Medan: Pengda PELTI Medan, 1994

Ralston. Dennis, Tennis Workbook, New Jersey, Prentice-Hall,1987

Saputra. Berkah, Bunadi, Dasar-Dasar Pelajaran Tenis, Bandung BBTS, 2001.

Sugiono, Metode Penelitian Kuanitatif, Kualitatif, dan $R \& D$, Bandung, Alfabeta, 1994

Yudoprasetio, Belajar Tenis, The Three Stroke Game, Jakarta,Bhratara Karya Aksara,1981 